\title{
Desempenho Sexual e Satisfação com Prótese Peniana em Impotência de Variada Etiologia
}

\author{
Comentá ios de Oswaldo a tins Rod igues Júnio ${ }^{1}$
}

ALLON, B HAN , H Desempenho sexual e satisfação com p ótese peniana em impotência de va iada etiologia International Journal of Impotence Research 2: 35-42, 1990.

De 252 pacientes que ecebe am implante de $\mathrm{p}$ ótese peniana, 142 devolve am um questioná io auto-administ ado A satisfação global foi ap oximadamente de $90 \%$, apesa das expectativas te em sido $\mathrm{p}$ eenchidas em apenas $74 \%$ Não se pe cebe am g andes difeenças ent e a p ótese inflável e a semi- ígida do pa âmet o de funcionamento sexual ais pacientes com p ótese semi- ígida senti am que fize am a escolha e ada (18\% compa ados a $6 \%$ de p ótese inflável) Os pa âmet os de funcionamento sexual fo am melho es nos pacientes com impotência vasculogênica e pio es naqueles com impotência devido a ci u gias adicais, nos quais as expectativas não fo am alcançadas em $38 \%$ A f eqüência das elações coitais declina am ao se compa a em a fase p é-mó bida e a de follow up $\mathrm{O}$ desejo sexual ficou p aticamente imutável As sensações penianas diminuí am em $38 \%$ A sensação o gásmica e o volume ejaculató io diminuiu em especial no g upo de impotentes devido a ci u gias adicais Vinte e cinco po cento desenvolveu demo a ou dificuldades em alcança o gasmos A satisfação da pa cei a sexual foi elatada em $80 \%$

1 Psicólogo clínico, psicote apeuta sexual do Instituto H llis (SP), p ofesso assistente de Teo ias e Técnicas Psicote ápicas II das aculdades São a cos (SP) Recebido em 280590 Ap ovado em 140890 
O questionário de 30 questões (abrangendo satisfação e função sexual no estágio pré-operatório; complicações operatórias e funcionamento atual da prótese; freqüência da atividade sexual e libido pós-operatório; ejaculação, orgasmo e sensações penianas pós-operatórios; opção e satisfação com a prótese; satisfação da parceira) foi mandado aos pacientes, junto com envelope selado para resposta. Apesar de 65\% dos pacientes não acharem útil passar por um psicólogo, 30\% passaram ao menos uma vez antes da cirurgia. Outros pacientes tiveram complicações pós-operatórias. Sete pacientes estavam com as próteses sem funcionamento.

O desejo sexual aumentou em $27,4 \%$ e diminuiu em $18 \%$.

$\mathrm{O}$ aumento da tumescência peniana durante a atividade sexual foi referido por $43 \%$, mormente entre pacientes vasculogênicos.

Os autores referem que o desconhecimento da opinião dos pacientes que não responderam ao questionário é um fato a se lamentar e um problema talvez insolúvel.

Tais estudos são de importância, pois, ao indicar a satisfação e a reação de pacientes quando da determinação do tipo de procedimento, auxiliam na manutenção da indicação e nas contra-indicações, o que talvez seja de maior importância. Desta forma, devemos crer que um estudo mais profundo sobre os pacientes que referiam insatisfação, que fizeram escolha errada ou que diminuíram a freqüência da atividade sexual, do desejo ou da sensibilidade peniana, enfim prejuízos, possa indicar quais fatores devem ser trabalhados anteriormente à implantação da prótese. Devemos crer que são fatores de ordem psicológica e solucionáveis através de intervenção psicoterapeuta. 